\title{
A Pre-Test via Partial Least Square Structural Equation Modeling with the Influence of Organisational Structures and Organisational Internal Factors on Construction Risk Management Among Malaysian Construction Industries
}

\author{
Manal Suliman Omer, A.Q. Adeleke, Chia Kuang Lee
}

\begin{abstract}
An increased demand has been placed on construction projects to be more accountable to their clients with measure to the company services and outputs. This demand is because of innumerable antecedent factors repelling risk management in construction projects. However, finishing the projects is not only the concern of the industries but also managing the risks involved with the projects. This paper investigated the effects of organizational structure and internal factors on the risk management among $G 7$ contractors in Malaysia. The purpose of this study is threefold: (i) to propose an inclusive research model which comprises of the antecedent factors proposed in the model to improve effective risk management in Malaysia construction industries (ii) to serve as a validation process for the developed instrument of the on-going research with the identified constructs of the study (iii) to show the preliminary analysis and the results. A pilot study was conducted, data was collected and a total of thirty (30) respondents' responses were analysed using a questionnaire of eighty-one items. This was conducted to access and validate how reliable the analytical tools (i.e PLS-SEM model) used in the survey were. The results obtained indicated that the reliability of the measurement model and the ensuing data for pilot study suggested a veritable evidence of their validity.
\end{abstract}

Keywords:-Construction, Coercive, Risk management, Instrument, Reliability assessment, and Validity assessment.

\section{INTRODUCTION}

The management of risk in a construction works is an integral part of the multidimensional processes involved when planning and executing projects. The quality of a construction project is determined by the ability to make necessary decisions regarding investment and management of possibly inherent risks (Anderson et al., 2006). There is possibility that the level of risk will reduce when it is identified in the process of planning a project, thereby leading to the prompt and successful completion of the construction project (Katsikea et al., 2011). The consideration of risks though interrelated can be considered

Revised Manuscript Received on April 12, 2019.

ManalSuliman Omer,Faculty of Industrial Management.University Malaysia Pahang, LebuhrayaTunRazak, 26300 Gambang, DarulMakmurKuantan, Pahang Malaysia. (manaltagot@gmail.com)

A.Q. Adeleke,Faculty of Industrial Management.University Malaysia Pahang, LebuhrayaTunRazak, 26300 Gambang, DarulMakmurKuantan, Pahang Malaysia.

Chia Kuang Lee, Faculty of Industrial Management.University Malaysia Pahang, LebuhrayaTunRazak, 26300 Gambang, DarulMakmurKuantan, Pahang Malaysia in isolation which has the effects of affecting the aims, objectives and the resultant success outcome of any construction projects

Different individual and organizational perception exist on construction projects with a particular reference to important components, origin, probabilities, consequences and preferred results as reported by (leggat 2007). The individual and general perception of people to a larger extent therefore influences the risk associated with construction projects as corroborated by (Barclay et al.,1995). The inherent bad performance in many construction work is therefore due to the inadequacy of risk assessment when the project is been planned and carried out and this could adversely affects the performance of such construction work. To therefore reduce the poor performance and failure of many construction works it is pertinent for the decision makers to take into consideration the risk assessment at the planning stage of the project in order to prevent organizational loss (Baron et al., 1986).

Also, it has been affirmed by various scholars (Assaf et al.,2016;Memoet al.,2011 ;Ahazie et al 2008; Adeleke et al.,2016)that some factors which pertains to the construction factors, organizational culture and structure factors such as formalization, specialization and centralization have remarkable correlationwith construction risks management. Therefore, to elucidate the inconclusive assertions on the relationship between the organizational internal factors and organizational structure, as well as construction risks management, a comprehensive framework there is required to integrate these factors through the use of a moderating roles of coercive pressure construction companies in Malaysia.

\section{LITERATURE REVIEW}

\section{ORGANIZATIONAL STRUCTURE}

Katsikea et al., (2011) defined organizational structure (formalization, centralization, specialization) as the framework that helps decision makers coordinates the organizational activities. Due to the differences in strategies

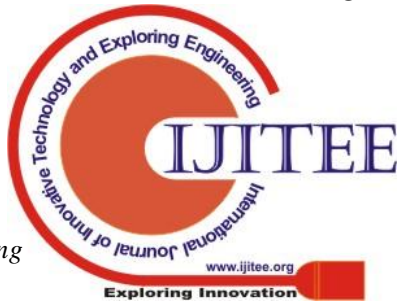


and environmental circumstances of many organizations, there are different types of organizational structures as reported by (Kasikea et al.,2011). A proper selection of these structures determines to a larger extent the success of construction work execution which aids the integration of stakeholders and reduction in capital expenditure.

The term formalization is defined as the volume of organizational documentation, which indicates the work done in relation to the formal regulations and procedures (Mohammed et al., 2017, Ahazie 2008). These rules and procedures are written to standardize operations in organizations. This is the measure of how employees carried out their individual work in accordance with the laid down organizational standard procedures and ethics. It is the extent to which a job is carried out or standardized in an organization within the framework of rules (Katsikea et al., 2011).

Specialization is described as the division of labour, or the procedure of dividing most of the activities required for the organization into individual tasks (Alqatawneh 2014). The entire philosophy of an organization is concentrated on the concept of the division of work and specialization. Therefore, the division of work is regarded as an assigned obligation to a particular person or a group of staff. Nevertheless, when the responsibility for a particular job is assigned to a designated expert in a field, it is called specialization. To ensure coordination, some of the workers occupy management positions at the different phases in the process (Altinay\&Altinay 2004).

\section{ORGANIZATIONAL INTERNAL FACTORS}

Effective communication is striking factors in business organization as inadequate communication could leads to an irreparable damage to the productivity and performance of any organization (Kikoski et al.,1999). This is an important ingredient which foster unity and commitment of all the workers and stakeholders in an organization (Leggat 2007). The success of any organizational success is therefore premised on how effective, and constant is the interaction among all workers is in a corporate establishment (Adeleke et al 2018).

Likewise,competency of a team and their skills are regarded as the basis for managing construction projects. These comprises of comprise skills, attitudes, knowledge, traits and values of the team members as reported by (Adeleke et al.,2015). Their dynamics is also related to the competency of the team, which is regarded as the quality which is required of a team for the successful execution of construction projects.

An effective leadership has contributing effects on the performance and success of any organization. In today's organizational settings, a leader is the individual responsible for clarifying direction through a line of actionsand then providing guidance and motivation for others to work towards executing the line of actions (Bakar et al.,2012; Adeleke et al.,2016).

Organisational culture is important factor has the capacity to affect how people set personal and professional goals, perform tasks and administer resources (Lok 2004). This is referred to as collective, basic assumptions that an organization learns while coping with the environment and solving problems of external adaptation and internal integration that new members are taught as the correct way to solve those problems.

\section{CONSTRUCTION RISK MANAGEMENT}

Risk management is mostly known as one of the most important capabilities and procedures in project management arena (Adeleke et al.,2016; Jarkas et al.,2015).The construction industry is associated with high degree of risk in nature, compared to other industries, is risky. Nevertheless, construction project is known to have more underlying risks due to many contracting parties, such as contractors, subcontractors, engineers, designers and clients that are involved.Construction projects are unique because they are built only once. The parties also include irregular project team members who are gatheredfrom different companies, countries and cultures. Thus, this situation has led to complexity and increase in size of construction projects thereby making the projects more liable to risks.

\section{MODERATING ROLE OF COERCIVE PRESSURE}

Coercive forces are the external pressures exerted by the government, regulatory, or other agencies to adopt the structures or favoured systems (Tempel et al.,2007). These pressures are often associated with legal requirements, health and safety regulations, but may also stem out of contractual obligations with other actors, which constrain organizational variety, as shown in Figure 1 conceptual framework.

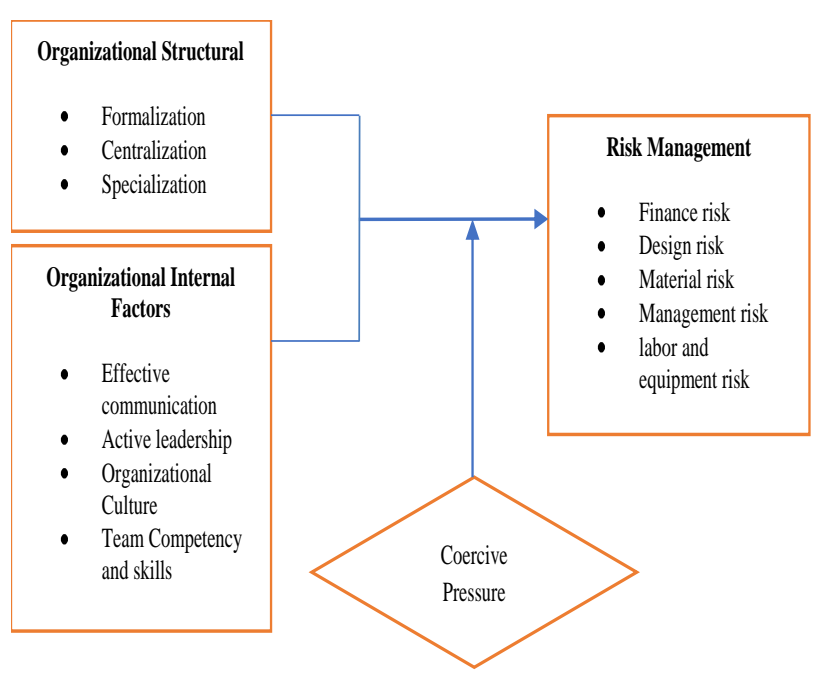

\section{METHODOLOGY}

This study adopted a cross-sectional research design. It means data were collected at a single-point-in-time using structured questionnaire (Jarkas et al.,2015). The research adopted the quantitative, approach, which is a method that is mostly adopted in the social sciences (Sekaran et al 2010). 
A small-scale study of respondents was adopted because it is a pilot study which is proposed for trial purposes before conducting the full-fledged study (Adeleke et al.,2016; Crede et al.,2011) Ideally, the sample size for pilot studies is proposed to be relatively smaller, ranging from 30 to 100 respondents.

Accordingly, this study presents the result of the pilot test with regard to the relationship between organizational structure, organizational internal factors, coercive pressure support, and construction risk management among Malaysian large contractors (The G7 contractors). A total of thirty-five (35) copies of questionnaire were administered personally. Thirty (30) copies were deemed suitable for analysis. Ordinarily, 30 to 100 respondents are considered appropriate for pilot testing (Malhotra, 2008). The responses collected were subsequently used for measuring.

In this study, the Partial Least Square (PLS) (Smarts PLS version 3.0) was employed to analyse the data.

\section{RELIABILITY AND VALIDITY ASSESSMENT\& RESULT}

In this study the respondents were selected from the local, national and other multinational construction company in Malaysia Peninsular and this comprises of both the civil and building construction companies. The reliability, validity and measurement accuracy was determined using the PLSGraph. Reliability is could be defined as how consistent an instrument is in terms of the time and across various items in the scale.Validity is regarded as the accuracy of how a construct reflect in what is been measured.In order to do this some certain characteristics measures are employed which include the content validity, convergent and discriminant validity.

Hopkins (2016) reported that the convergence and discriminant validity help in creating the correlation between a measuring instrument and the specific theory by taking onto consideration the measuring scales which is the representation of a correct attributes.Factors such as loadings, composite reliability and Average Variance Extracted (AVE) are important parameters employed in the measurement of convergence validity as supported (Hair et al.,2013).

Moreover, the factor loadings and cross loadings are employed for the discovery of any challenge with an item of choice.This preliminary study shows that the items loaded are effective in relation to their constructs with the value above recommended 0.5 standard measures (Sarstedt et al.,2017) with the lower and upper range of 0.609 and 0.909 , respectively.

In the same vein, the highest and lowest composite reliability and average variance extracted ranged between $(0.926,0.837,0.79$ and 0.57$)$ respectively. 


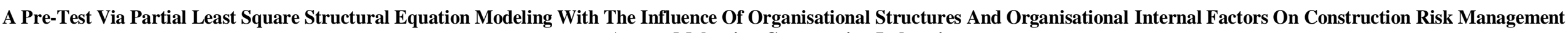
Among Malaysian Construction Industries

Table 4. Discriminant Validity

\begin{tabular}{|c|c|c|c|c|c|c|c|c|c|c|c|c|c|}
\hline & ACTI & CETERA & COERCIEVE & DESIGN & $\mathrm{EFFE}_{-}$ & FINANCE & FOR & LIBOUR.EQ & MANAGE & MATERIAL & $\mathrm{O} . \mathrm{CU}$ & $\begin{array}{l}\text { SPEC- } \\
-\end{array}$ & $\begin{array}{l}\text { TEAM } \\
\text { COMP } \\
\end{array}$ \\
\hline ACTIVE LEADER & 0.768 & & & & & & & & & & & & \\
\hline CETERALISATION & 0.046 & 0.757 & & & & & & & & & & & \\
\hline COERCIEVE & 0.533 & 0.32 & 0.826 & & & & & & & & & & \\
\hline DESIGN & 0.626 & 0.142 & 0.641 & 0.824 & & & & & & & & & \\
\hline $\begin{array}{l}\text { EFFECTIVE } \\
\text { COMMU }\end{array}$ & 0.746 & -0.092 & 0.305 & 0.53 & 0.818 & & & & & & & & \\
\hline FINANCE & 0.57 & 0.134 & 0.58 & 0.595 & 0.438 & 0.89 & & & & & & & \\
\hline FORMALISATION & 0.16 & 0.412 & 0.171 & 0.112 & 0.179 & 0.148 & 0.819 & & & & & & \\
\hline LIBOUR.EQ & 0.711 & 0.021 & 0.719 & 0.693 & 0.678 & 0.594 & 0.281 & 0.846 & & & & & \\
\hline MANAGE & 0.592 & 0.105 & 0.726 & 0.637 & 0.596 & 0.495 & 0.239 & 0.839 & 0.854 & & & & \\
\hline MATERIAL & 0.399 & 0.43 & 0.533 & 0.585 & 0.366 & 0.501 & -0 & 0.398 & 0.459 & 0.837 & & & \\
\hline O.CULTURE & 0.64 & 0.125 & 0.643 & 0.537 & 0.693 & 0.608 & 0.211 & 0.643 & 0.639 & 0.515 & 0.792 & & \\
\hline SPECIALISATION & 0.651 & 0.304 & 0.521 & 0.644 & 0.507 & 0.354 & 0.229 & 0.643 & 0.62 & 0.453 & 0.298 & 0.755 & \\
\hline TEAM COMP & 0.732 & 0.198 & 0.627 & 0.693 & 0.652 & 0.53 & 0.272 & 0.797 & 0.743 & 0.411 & 0.514 & 0.703 & 0.849 \\
\hline
\end{tabular}

** Note the diagonal values in orange colour the average variance extracted (AVE) while the other entries signify the squared correlations. 


\section{CONCLUSION AND DISCUSSION}

It is important to note that this study entails the presentation of the research model and the establishments of relationship between latent variables (i.e. exogenous and endogenous).In addition, this study explored the validity and reliability using the PLS-SEM measuring instruments in the main survey. This was found from previous investigation to understand the perspective of academia and those involved in the construction work on the management of risk on the field. This will help to effectively manage and makes a positive policy that will ensure the success and high performance of the construction industry.

Moreover, the results obtained from the PLS-SEM assisted in the confirm that the items used in this study are more encircling and for the measurement most importantly in the consideration of benchmarks set for composite reliability, standardized loading and the average variance extracted. In this study, a explicit reference was made to the content validity, convergent and discriminant validity which were conducted ascertain the construct validity in this study.Accordingly, the result indicated that the measuring instruments are consistent and the data for this pilot study suggests a strong evidence of rational validity. The pre-test analysis result of this research has established that the variables presented were above the threshold 0.5-point value and are appropriate to be used in the main data collection. The reliability analysis is therefore expected to be carried out on the main data collected after conducting factor analysis on the main study based on a sample size.

\section{REFERENCES}

1. Bahamid, R. A., \& Doh, S. I. (2017). A review of risk management process in construction projects of developing countries. IOP Conference Series: Materials Science and Engineering, 271(1). https://doi.org/10.1088/1757899X/271/1/012042

2. Bakar, A., Bin, A. H., Ali, K., Onyeizu, E. N., \& Yusof, M. N. (2012). EVALUATING RISK MANAGEMENT PRACTICES IN CONSTRUCTION INDUSTRY: EVIDENCE FROM OMAN. International Journal of Academic Research, 4(2).

3. Yusuwan, N. M., Adnan, H., \& Omar, A. F. (2008). Clients ' Perspectives of Risk Management Practice in Malaysian Construction Industry. 